ORIGINAL ARTICLE

\title{
Abnormally high serum ferritin levels among professional road cyclists
}

\author{
H Zotter, N Robinson, M Zorzoli, L Schattenberg, M Saugy, P Mangin
}

Br J Sports Med 2004;38:704-708. doi: 10.1136/bjsm.2003.006635

See end of article for authors' affiliations

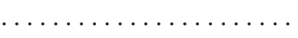

Correspondence to: Harald Zotter, Institut Universitaire de Medicine Legale, Laboratoire Suisse d'Analyse du Dopage, 21 rue du Bugnon, Lausanne 1005, Switzerland: hzotter@hospvd.ch

Accepted 28 September 2003
Background: An international, longitudinal medical follow up examination of male professional road cyclists revealed excessively elevated serum ferritin levels.

Objective: To evaluate the importance of elevated ferritin values among professional cyclists, their relationship with age and nationality, and their evolution over 3 years.

Methods: Over 1000 serum ferritin values were collected. Other parameters were included in order to exclude conditions which might have increased ferritin levels without changing body iron stores.

Results: In 1999, over $45 \%$ of riders displayed ferritin values above $300 \mathrm{ng} / \mathrm{ml}$ and one fourth levels over $500 \mathrm{ng} / \mathrm{ml}$. These percentages had decreased to $27 \%$ and $9 \%$, respectively, 3 years later, while the overall average, which was above the normal limits in 1999, had decreased by $33 \%$ in 3 years. Older cyclists had higher ferritin values than younger cyclists. There was also a relationship between ferritin levels and the nationality of the cyclists. Analysis of 714 riders in 2000 and 2002 showed only a slight and insignificant decrease in the mean ferritin value although those with initially elevated iron stores had a much greater decrease.

Conclusion: Professional road cyclists used excessive iron supplementation leading to high serum ferritin levels correlating with increased body iron stores. Although the situation progressively improved over 3 years, it remains worrying as increased body iron stores are related to health complications. Therefore, prevention in addition to the fight against doping should be a main goal of the $\mathrm{UCl}$. Aggressive therapy for athletes with excessive ferritin values should be carried out at or before the end of their careers.
S pectacular doping stories during the past few years have seriously affected the credibility of high level sports. The media have been more interested in chasing doping scandals than in reporting on real performances, about which in any case doubts are often raised. International sports federations and athletes have therefore tried to re-establish a fair and healthy perception of sporting events. As a result, in 1999, the International Sports Federation of Cycling (Union Cycliste Internationale, UCI) introduced a longitudinal medical follow up examination whose main goal was to protect the health of the riders. Four times a year blood tests, including a full blood count with reticulocytes, and routine chemistry analyses to examine ferritin, testosterone, cortisol, and TSH are carried out. These tests are accompanied by a full medical check up with emphasis on the heart. Since 1999, the UCI medical follow up examination has been mandatory for all professional road cyclists registered in a first or second category trade team (approximately 1100 international athletes or around 60 professional cycling teams). The first and most obvious abnormality revealed by this medical survey was the high serum ferritin levels in many athletes.

About 30 years ago, it was proposed that serum ferritin correlates quite accurately with body iron stores. ${ }^{12}$ This was confirmed in the following years and recently by Beutler et al. ${ }^{3}$ Serum ferritin assessment is relatively simple and therefore is the most commonly used indicator of body iron stores.

Iron is essential for cellular life and is required in numerous metabolic processes, one of the most important being erythropoiesis. In normal healthy individuals, there are about $35 \mathrm{mg}$ of iron per kg body weight in adult women and $45 \mathrm{mg} / \mathrm{kg}$ in adult males. ${ }^{45}$ About $65 \%$ of body iron is carried in the haemoglobin of circulating red blood cells, while another $10 \%$ is incorporated in myoglobin, cytochromes, and iron containing enzymes. The remaining $20-30 \%$ is stored in ferritin and haemosiderin. ${ }^{6}$ Distribution within these stores can change under various conditions, such as inflammation and increased erythrocyte production, or when absorption is abnormally increased as seen in haemochromatosis.

Iron is vital but also highly toxic when not maintained within cells or bound to proteins. The danger of free iron is believed to be due to its ability to generate tissue damaging free radicals. ${ }^{78}$ These highly reactive oxygen species can interact rapidly with high affinity with almost every molecule found in living cells. Iron can also react directly with unsaturated fatty acids thus impairing cellular integrity and causing cell death. ${ }^{9}{ }^{10}$ Because of these deleterious effects, iron is thought to play an important role in carcinogenesis, the pathogenesis of atherosclerosis, and neurodegenerative disorders. ${ }^{10-15}$ Another health damaging effect of iron overload is the increased risk of infections: microorganisms use iron for metabolic functions and excessive free iron facilitates bacterial cell growth. In addition, normal defence mechanisms could be altered. ${ }^{16}$

The long term consequences of iatrogenic iron excess are not known, but may be similar to hereditary haemochromatosis. Excessive iron can deposit in the form of aggregates in various tissues particularly the liver, pancreas, heart, joints, skin, and pituitary gland. This could ultimately lead to irreversible organ dysfunction such as cirrhosis and to cancer as is described in haemochromatosis.

Given the health risks described above, the fact that many cyclists had high ferritin levels was worrying. As soon as the first signs of iron overload appeared in $1996,{ }^{17}$ the UCI informed teams about the risks of iron overload and basic guidelines on how to deal with athletes with hyperferritinaemia were introduced.

Abbreviations: rhEPO, recombinant human erythropoietin; $\mathrm{UCl}$, Union Cycliste Internationale 
The aim of this paper is to describe the iron overload problem among male professional road cyclists, its relationship with age and nationality, and most interestingly its evolution over 3 years.

\section{METHODS \\ Subjects}

Over 1000 male international professional cyclists were included in the UCI longitudinal medical follow up examination (table 1), which was mandatory for all first and second category professional cycling teams, officially called trade teams. All serum ferritin values were collected between December and January and since 2000 have been stored in a computer database. Unfortunately, for technical reasons, only 444 values were collected in the first year (table 1).

\section{Pre-analytical conditions}

Pre-analytical conditions could not be checked individually, but according to UCI rules, blood tests must be carried out in the morning, ideally at 8:00 am, during fasting. It is also stated that no intensive exercise should be done in the previous $24 \mathrm{~h}$.

\section{Analysis}

Analyses were performed on venous blood samples in laboratories from various countries around the world accepted by the UCI. Each laboratory analysed serum ferritin according to its own good laboratory practice (it has been demonstrated that there is a good correlation between available commercial kits $^{18}{ }^{19}$ ). The normal range in this study was set at $20-300 \mathrm{ng} / \mathrm{ml}$.

C-reactive protein was routinely determined and liver function tests (gamma-glutamyltranspeptidase (GGT), aspartate aminotransferase (AST, SGOT), alanine aminotransferase (ALT, SGPT), alkaline phosphates, and bilirubin) were also carried out. These results are not shown. Except for isolated and slight elevations of ALT which were transient and related to heavy training, all other parameters were within normal range.

\section{Statistics}

Cyclists were classified by age and nationality. Mean and standard errors of the mean (SEM) were calculated for overall serum ferritin values and for the different groups. ANOVA one way analysis of variance was applied to compare more than two groups. The modified Welsh test was used to compare the results of two groups. $\mathrm{p}<0.05$ was considered to be significant.

\section{RESULTS}

The distribution of serum ferritin values among the professional cyclists included in the 2002 medical follow up examination is shown in fig 1 . In previous years, the distribution curve was similar, with a typical "stretch" to the right, except that the peak of the curve was less broad and the left slope was less steep.

The mean serum ferritin values of the professional road cyclists are shown in table 1. The average values decreased regularly each year, with a decrease of 33\% from 1999 to

Table 1 Number of ferritin values analysed

\begin{tabular}{lllll}
\hline & 1999 & 2000 & 2001 & 2002 \\
\hline Ferritin & $359(14.8)$ & $277(7.2)$ & $255(6.7)$ & $242(5.9)$ \\
$n$ & 444 & 1079 & 1105 & 1139
\end{tabular}

Ferritin values are mean (SEM)

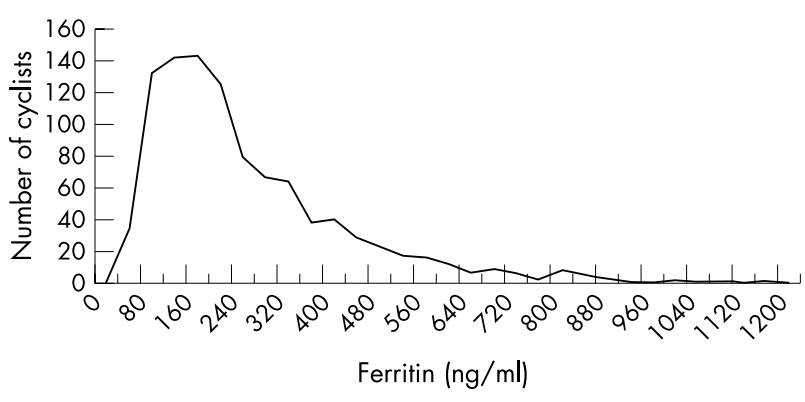

Figure 1 Distribution of serum ferritin values among professional road cyclists in 2002.

2002. There is a statistical difference between each year, except between 2001 and 2002.

The percentage of cyclists with ferritin levels over 300 and $500 \mathrm{ng} / \mathrm{ml}$ also decreased with time as shown in table 2 .

Figure 2 shows that there was a relationship between age and ferritin level. The oldest and youngest groups of cyclists were statistically different from all others. Comparison between the other age groups did not show statistical difference. With time, there was a decrease in the mean values in each age group, except for the two youngest groups born after 1975, which initially had normal values. There was no statistical difference between the years. Analysis for 1999 was not carried out due to lack of data.

There was also a close relationship between the nationality of the riders and serum ferritin levels (fig 3). The decrease from 2000 to 2002 is statistically significant only in groups $\mathrm{A}-\mathrm{C}$, which had the highest initial values. There is also a statistical difference between 2000 and 2002 in group $\mathrm{H}$ which displayed an increase in the average value.

Analysis of the same 714 riders screened in 2000 and 2002 showed that average ferritin value decreased by $5 \%$ without statistical difference. The same 94 athletes with levels above $500 \mathrm{ng} / \mathrm{ml}$ in 2000 displayed an average decrease of 24\% 2 years later, while the same 37 riders with values above $700 \mathrm{ng} / \mathrm{ml}$ showed a decrease of $27 \%$. The decrease in both groups with initially high ferritin levels was statistically significant (fig 4). The remaining athletes showed an increase of $4.8 \%$ over the 2 years.

According to UCI rules, athletes with levels above $500 \mathrm{mg} /$ $\mathrm{ml}$ on two consecutive tests had to consult a haematologist or a gastro-enterologist. Further investigations such as hepatic echography with or without biopsy confirmed iron deposits, but no tissue damage has been recorded. Mutation of the HFE gene was demonstrated in seven riders of whom three were homozygous for $\mathrm{C} 282 \mathrm{Y}$, one heterozygous for $\mathrm{C} 282 \mathrm{Y}$, one homozygous for H63D, three heterozygous for H63D, and one compound homozygous.

The average haemoglobin and haematocrit values were around $15.0 \mathrm{~g} / \mathrm{dl}$ and $44.0 \%$, respectively, with no difference between the year of birth.

\section{DISCUSSION}

The longitudinal medical follow up examination introduced by the UCI in 1999 confirmed high serum ferritin levels revealed in 1996 in professional road cyclists. ${ }^{17}$ Results previously published by the French cycling federation showed that one third of 83 tested elite French cyclists had ferritin levels greater than $300 \mathrm{ng} / \mathrm{ml}$ in $1998 .^{20}$ In the present international survey of more than 1000 athletes, $45 \%$ of the riders displayed ferritin values above $300 \mathrm{ng} / \mathrm{ml}$ and one fourth had ferritin levels over $500 \mathrm{ng} / \mathrm{ml}$ in 1999. The average value was $342 \mathrm{ng} / \mathrm{ml}$, which is above the upper normal limit of $300 \mathrm{ng} / \mathrm{ml}$ commonly used by laboratories and in the scientific literature. ${ }^{20-23}$ This situation was quite the opposite 
Table 2 Distribution of ferritin values among elite cyclists and evolution over 3 years

\begin{tabular}{|c|c|c|c|c|c|c|c|c|c|c|c|c|}
\hline & \multicolumn{3}{|c|}{1999} & \multicolumn{3}{|c|}{2000} & \multicolumn{3}{|c|}{2001} & \multicolumn{3}{|c|}{2002} \\
\hline & $n$ & $\%$ & SEM & n & $\%$ & SEM & $\mathbf{n}$ & $\%$ & SEM & n & $\%$ & SEM \\
\hline A & 243 & 54.7 & 4.6 & 724 & 67.1 & 2.8 & 773 & 70.0 & 2.6 & 832 & 73.2 & 2.5 \\
\hline B & 91 & 20.5 & 5.6 & 207 & 19.2 & 3.9 & 208 & 18.8 & 4.0 & 198 & 17.4 & 3.9 \\
\hline C & 110 & 24.8 & 29.4 & 148 & 13.7 & 21.1 & 124 & 11.2 & 24.7 & 107 & 9.4 & 19.5 \\
\hline
\end{tabular}

of that usually observed in trained athletes. In general, serum ferritin levels are lower in athletes than in sedentary persons, mostly within normal range, but up to $10 \%$ of male athletes have been reported to have insufficient iron stores. ${ }^{24} 25$

The increased serum ferritin levels were related to increased body iron content. Indeed, there is a good correlation between both parameters. ${ }^{1-3}$ In addition, the interviewed cyclists reported excessive iron supplementation, mainly by repeated intravenous administration. Other conditions that might have increased serum ferritin levels, such as inflammation or pseudo-inflammation caused by strenuous exercise, infection, liver disease, or malignancy, could be reasonably ruled out as other acute phase reactants tested concomitantly were within normal range.

Court trials and the media, especially after the Tour de France scandal in 1998, have already revealed one reason for excessive iron intake. The use of erythropoietic stimulants, such as recombinant human erythropoietin (rhEPO), increases the need for iron so much that it exceeds the physiological occurring reserves in storage tissue. Furthermore, increasing body iron levels before rhEPO administration improves the resulting erythropoiesis. ${ }^{26-32}$ These facts explain why athletes who use rhEPO also take iron supplementation, mostly by parenteral access.

Nevertheless, it is important to emphasis that high ferritin levels are not proof of former or actual blood doping. In fact, one could say that iron is part of the culture of cycling. Even before rhEPO became available in 1989, iron supplements were used regularly, as witnessed by former team doctors. This situation was due to the widespread beliefs among cyclists that iron was a fortifying drug that increase the number of red blood cells and thus performance. This of course is only true for those suffering from iron deficiency. Another reason why athletes took iron supplementation was low serum iron. Unfortunately, serum iron can be normal or even decreased despite high body iron stores. ${ }^{33}{ }^{34}$

In this study, ferritin levels showed an overall decrease with time. From 1999 to 2002 the average ferritin values decreased by $33 \%$ and the percentage of riders with levels below $300 \mathrm{ng} / \mathrm{ml}$ increased from a little more than a half to almost three quarters.

Another major finding was the strong relationship between age and ferritin levels, probably due to chronic use of iron supplementation by older riders at a time when the overload problem was not as obvious and medical supervision was not mandatory.

The fact that older cyclists displayed the greatest lowering of ferritin levels could result from the fact that at the end of their cycling careers they were replaced by younger athletes with normal iron stores. This worrying hypothesis is supported by the fact that iron undergoes an almost closed metabolic cycle. Indeed, even in cases of iron excess, there is hardly any adaptation of elimination, which does not exceed $2 \mathrm{mg} /$ day, except in the case of bleeding. ${ }^{35}{ }^{36}$ On the other hand, physical activity increases iron turnover and the situation could be different in elite sportsmen. ${ }^{37}$
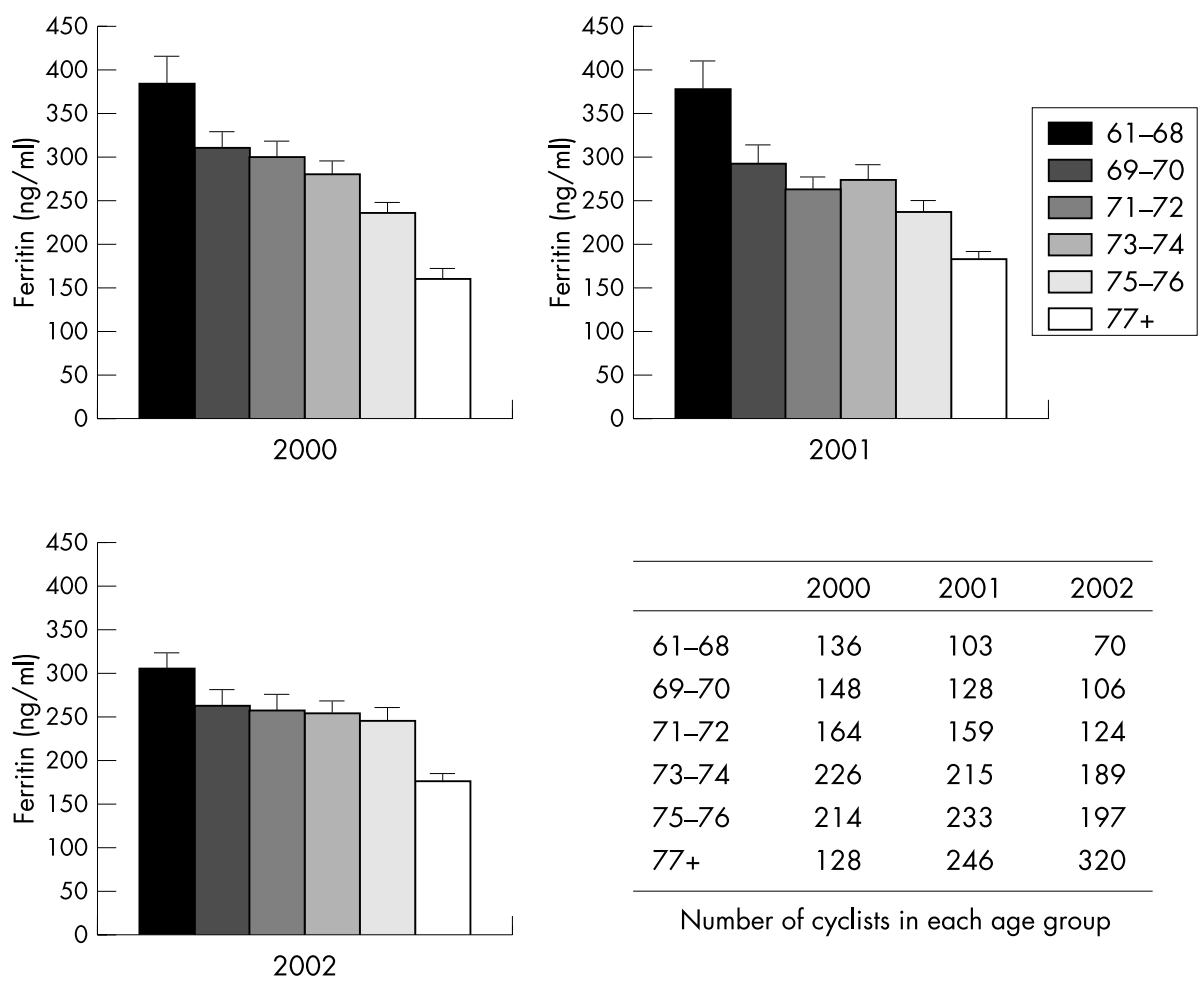

\begin{tabular}{lccc}
\hline & 2000 & 2001 & 2002 \\
\hline $61-68$ & 136 & 103 & 70 \\
$69-70$ & 148 & 128 & 106 \\
$71-72$ & 164 & 159 & 124 \\
$73-74$ & 226 & 215 & 189 \\
$75-76$ & 214 & 233 & 197 \\
$77+$ & 128 & 246 & 320 \\
\hline
\end{tabular}

Number of cyclists in each age group
Figure 2 Mean serum ferritin levels (SEM) over 3 years according to year of birth of the cyclists. "61-68" etc indicates year of birth. 

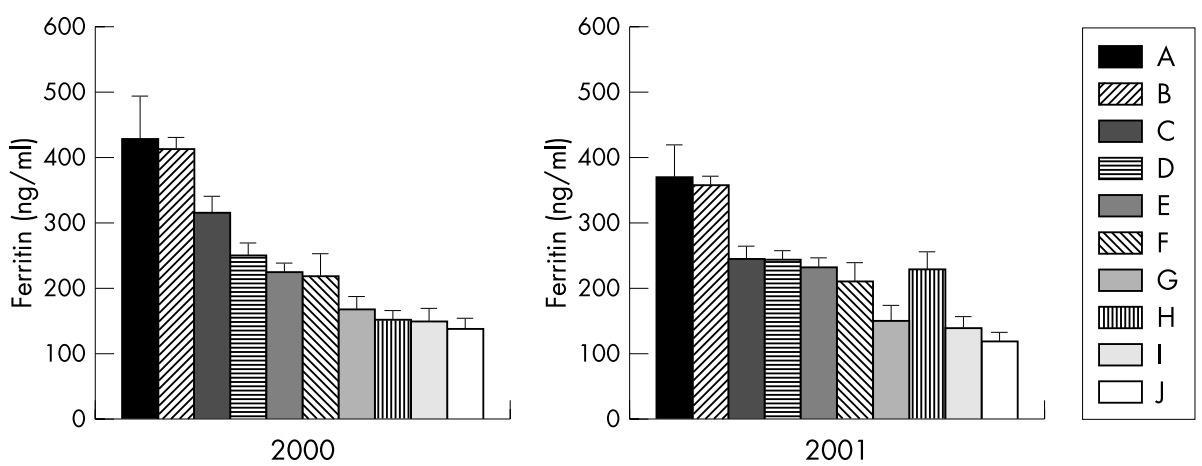

Figure 3 Evolution over 2 years of the mean serum ferritin level (SEM) of male professional cyclists according to nationality.

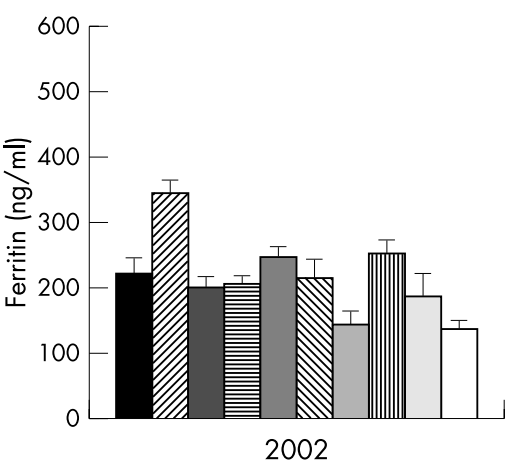

\begin{tabular}{rrrr}
\hline & 2000 & 2001 & 2002 \\
\hline A & 34 & 24 & 53 \\
B & 215 & 241 & 164 \\
C & 116 & 121 & 117 \\
D & 95 & 117 & 110 \\
E & 145 & 154 & 179 \\
F & 39 & 31 & 27 \\
G & 64 & 61 & 80 \\
H & 34 & 24 & 53 \\
I & 37 & 42 & 19 \\
J & 46 & 47 & 39 \\
\hline \multicolumn{4}{r}{ Number of riders of each nationality }
\end{tabular}

The average ferritin values of the same 714 riders in 2000 and 2002 showed a decrease of only 5\%, compared to 13\% for the overall values. This would support the hypothesis that the improvement was only due to the fact that older cyclists, with high ferritin levels, dropped out of the UCI medical follow up. On the other hand, individual ferritin profiles displayed a totally random evolution in many riders, with variations of up to $800 \%$. This was most probably related to the use of erythropoietic stimulants or to blood transfusions. The most suspect athletes are those who displayed a major decrease in ferritin levels in short time.

The use of iron and/or rhEPO during the study makes it difficult to draw definite conclusions. Nevertheless, athletes

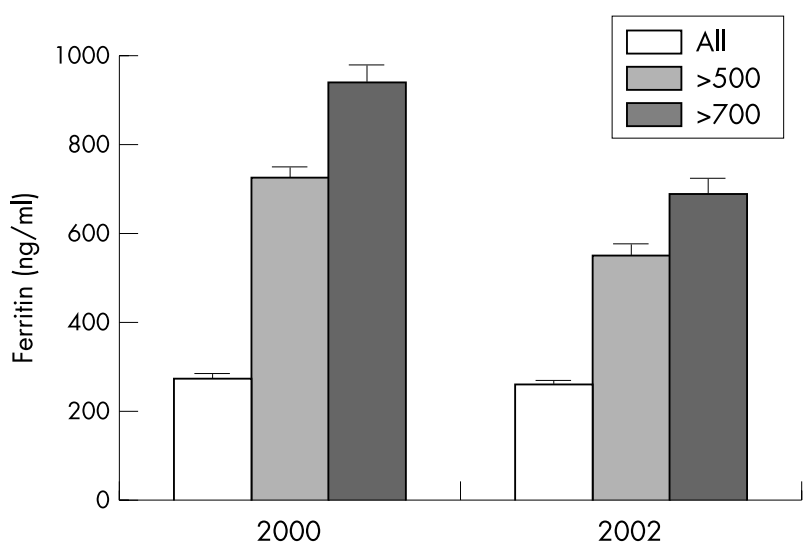

Figure 4 Mean ferritin values (SEM) of the same cyclists in 2000 and 2002. "All" indicates the group of 714 athletes, "> $>500^{\prime \prime}$ indicates the subgroup of these athletes with values above $500 \mathrm{ng} / \mathrm{ml}$, and " $>700$ " indicates those with values above $700 \mathrm{ng} / \mathrm{ml}$. with ferritin levels over $500 \mathrm{ng} / \mathrm{ml}$ generally showed a more stable profile, with levels tending to decrease as confirmed by the average values. It seems that the higher initial ferritin value was, the greater was the decrease. Decreases were observed in each age group, especially the older ones. These findings suggest that the overall decrease was not due solely to the fact that older cyclists drop out.

This study also revealed a close relationship between the nationality of the cyclist and ferritin levels. This was linked to the above mentioned beliefs. Indeed, one could say that there were national habits and some countries used iron supplementation, especially parenteral iron, more often than others.

The long term health consequences of this situation are currently unknown. Complications such as those described in haemochromatosis are likely and cyclists with increased serum ferritin levels probably have an increased risk of developing cirrhosis, cancer, cardiovascular diseases, and neurodegenerative disorders. ${ }^{10-15}$

Aggressive therapy, such as bleeding, for those riders with high ferritin levels is probably necessary once they finish their careers. However, iron elimination may be higher in elite endurance athletes than in untrained individuals. However, medical follow up is only mandatory for licensed athletes and so others not properly informed may seek medical advice only after complications have appeared. Therefore every athlete with increased iron stores should receive medical advice.

To conclude, in professional cycling there was excessive use of parenteral iron, which was related to blood doping and to very strong beliefs that are part of the culture of cycling. The situation seemed to be improving slowly with time, but is still worrying. The only way to improve the situation further is to continue the fight against doping and educate the athletes. Both aspects are closely related and are part of the health program introduced by the UCI. 


\section{What is already known on this topic}

Only two articles have been recently published on excessive iron supplementation by cyclists, while other articles on iron overload are related to pathological situations such as rhEPO treatment or haemochromatosis. Normally in sports it is iron deficiency not excess that is highlighted.

\section{What this study adds}

This is the first longitudinal international study of the serum ferritin levels of more than 1000 elite road cyclists. It reveals that the problem is greater than suspected and that there is a relationship between the nationality as well as the ages of the cyclists and the iron overload problem.

\section{Authors' affiliations}

H Zotter, N Robinson, M Saugy, P Mangin, Laboratoire Suisse d'Analyse du Dopage, Institut Universitaire de Médecine Légale, Lausanne, Switzerland

M Zorzoli, L Schattenberg, Union Cycliste Internationale, CH 1860 Aigle, Switzerland

Conflict of interest: none declared.

\section{REFERENCES}

1 Cook JD, Lipschitz DA, Miles LE, et al. Serum ferritin as a measure of iron stores in normal subjects. Am J Clin Nutr 1974;27:681-7.

2 Walters GO, Miller FM, Worwood M. Serum ferritin concentration and iron stores in normal subjects. J Clin Pathol 1973;26:770-2.

3 Beutler E, Felitti V, Ho NJ, et al. Relationship of body iron stores to levels of serum ferritin, serum iron, unsaturated iron binding capacity and transferrin saturation in patients with iron storage disease. Acta Haematol 2002;107:145-9.

4 Andrews NC. Disorders of iron metabolism. N Engl J Med 1999;341:1986-95.

5 Andrews NC. The iron transporter DMT1. Int J Biochem Cell Biol 1999:31:991-4

6 Conrad ME, Umbreit JN, Moore EG. Iron absorption and transport. Am J Med Sci 1999;318:213-29

7 Kehrer JP. The Haber-Weiss reaction and mechanisms of toxicity. Toxicology 2000;149:43-50.

8 Parkkinen J, von Bonsdorff L, Peltonen S, et al. Catalytically active iron and bacterial growth in serum of haemodialysis patients after i.v. iron-saccharate administration. Nephrol Dial Transplant 2000;15:1827-34.

9 McCord JM. Iron, free radicals, and oxidative injury. Semin Hematol 1998;35:5-12.

10 Gerlach M, Ben-Shachar D, Riederer P, et al. Altered brain metabolism of iron as a cause of neurodegenerative diseases? J Neurochem 1994;63:793-807. 11 Fracanzani AL, Conte D, Fraquelli $M$, et al. Increased cancer risk in a cohort of 230 patients with hereditary hemochromatosis in comparison to matched control patients with non-iron related chronic liver disease. Hepatology 2001;33:647-51

12 Mallory MA, Kowdley KV. Hereditary hemochromatosis and cancer risk: more fuel to the fire? Gastroenterology 2001;121:1253-4.

13 Sullivan JL. Iron therapy and cardiovascular disease. Kidney Int Suppl 1999;69:S135-7

$14 \mathrm{Ma} \mathrm{J}$, Stampfer MJ. Body iron stores and coronary heart disease. Clin Chem 2002;48:601-3.

15 Kletzmayr J, Horl WH. Iron overload and cardiovascular complications in dialysis patients. Nephrol Dial Transplant 2002; 17(suppl 2):25-9.

16 Patruta SI, Edlinger R, Sunder-Plassmann G, et al. Neutrophil impairment associated with iron therapy in hemodialysis patients with functional iron deficiency. J Am Soc Nephrol 1998:9:655-63.

17 Robinson N, Mangin P, Schattenberg L, et al. Origine du suivi hématologique: les contrôles hématocrites dans le cyclisme. Rev Fr Lab 2003;350:67-73.

18 Wood WG. A comparison of eleven commercial kits for the determination of serum ferritin levels. J Clin Chem Clin Biochem 1981;19:947-52.

19 Lacobello C, Ghielmi S, Belloli S, et al. Use of a reference standard to improve the accuracy and precision of seven kits for determination of ferritin in serum. Clin Chem 1984;30:298-301.

20 Deugnier $Y$, Loreal $O$, Carre $F$, et al. Increased body iron stores in elite road cyclists. Med Sci Sports Exerc 2002;34:876-80.

21 Anderson MG, Kelly AM. Serum ferritin by a rapid and inexpensive ELISA method. Clin Chim Acta 1981;116:405-8.

22 Robinson N, Schweizer C, Cardis C, et al. Haematological and biochemical parameters from all professional cyclists during the Tour de Suisse. Schwiez Z Sportmed Sporttraumatol 2000;48:104-10.

23 Milman N, Ovesen L, Byg K, et al. Iron status in Danes updated 1994. I: Prevalence of iron deficiency and iron overload in 1332 men aged 40-70, Influence of blood donation, alcohol intake, and iron supplementation. Ann Hematol 1999;78:393-400.

24 Newhouse IJ, Clement DB. Iron status in athletes: an update. Sports Med 1988;5:337-52.

25 Schumacher YO, Schmid A, Grathwohl D, et al. Hematological indices and iron status in athletes of various sports and performance. Med Sci Sports Exerc 2002;34:869-75.

26 Eschbach JW, Abdulhadi MH, Browne JK, et al. Recombinant human erythropoietin in anemic patients with end-stage renal disease. Results of a phase III multicenter clinical trial. Ann Intern Med 1989;111:992-1000.

27 Eschbach JW, Egrie JC, Downing MR, et al. Correction of the anemia of endstage renal disease with recombinant human erythropoietin. Results of a combined phase I and II clinical trial. N Engl J Med 1987;316:73-8.

28 Macdougall IC, Hutton RD, Cavill I, et al. Poor response to treatment of renal anaemia with erythropoietin corrected by iron given intravenously. BMJ 1989;299:157-8

29 Van Wyck DB. Iron management during recombinant human erythropoietin therapy. Am J Kidney Dis 1989;14(2 suppl 1):9-13.

30 Kirlin LF. Case management of the anemic patient: epoetin alfa-focus on iron supplementation. ANNA J 1993;20:678-81.

31 Adamson JW. The relationship of erythropoietin and iron metabolism to red blood cell production in humans. Semin Oncol 1994;21(2 suppl 3):9-15.

32 Major A, Mathez-Loic F, Rohling R, et al. The effect of intravenous iron on the reticulocyte response to recombinant human erythropoietin. $\mathrm{Br} J$ Haematol 1997;98:292-4.

33 Moirand R, Mortaji AM, Loreal O, et al. A new syndrome of liver iron overload with normal transferrin saturation. Lancet 1997:349:95-7.

34 Nielsen P, Nachtigall D. Iron supplementation in athletes. Sports Med 1998;26:207-16.

35 Haen PJ. Iron deficiency anaemia. In: Harris Young L, ed. Principles of Hematology. Dubuque, IA: William C, Brown, 1995:118-25.

36 Andrews NC. Disorders of iron metabolism. N Engl J Med 1999;341:1986-95

37 Clarkson PM, Haymes EM. Exercise and mineral status of athletes: calcium magnesium, phosphorus and iron. Med Sci Sports Exerc 1985;27:176-9. 